BULLETIN Bulletin hispanique

HISPANIQUE Université Michel de Montaigne Bordeaux

$120-2$ | 2018

Varia

\title{
Don Rodrigo de Valdepeñas y la primera edición de la Glosa a las Coplas de Jorge Manrique (1540)
}

Don Rodrigo de Valdepeñas et la première édition de la Glosa aux Coplas de Jorge Manrique (1540)

Don Rodrigo de Valdepeñas and the first edition of the "Glosa" in addition to Jorge Manrique's “Coplas” (1540)

\section{Giuseppe Seche}

\section{OpenEdition}

\section{Journals}

Edición electrónica

URL: https://journals.openedition.org/bulletinhispanique/6943

DOI: 10.4000/bulletinhispanique.6943

ISSN: 1775-3821

\section{Editor}

Presses universitaires de Bordeaux

\section{Edición impresa}

Fecha de publicación: 10 diciembre 2018

Paginación: 565-580

ISBN: 979-10-300-0337-6

ISSN: 0007-4640

\section{Referencia electrónica}

Giuseppe Seche, «Don Rodrigo de Valdepeñas y la primera edición de la Glosa a las Coplas de Jorge Manrique (1540)», Bulletin hispanique [En línea], 120-2 | 2018, Publicado el 02 enero 2022, consultado el 08 enero 2022. URL: http://journals.openedition.org/bulletinhispanique/6943 ; DOI: https://doi.org/ 10.4000/bulletinhispanique.6943 


\title{
Variétés
}

\section{Don Rodrigo de Valdepeñas y la primera edición de la Glosa a las Coplas de Jorge Manrique (1540)}

\author{
Giuseppe Seche \\ Università degli Studi di Cagliari
}

\begin{abstract}
Don Rodrigo de Valdepeñas et la première édition de la Glosa aux Coplas de Jorge Manrique (1540)

L'article étudie deux copies de la Glosa de Rodrigo de Valdepeñas (1505-1560) aux Coplas por la muerte de su padre de Jorge Manrique (1440-1479): la première est conservée à la Bayerische Staatsbibliothek de Munich, la seconde dans la Bibliothèque de la Hispanic Society of America de New York. Il ressort de l'analyse que les deux documents sont des copies de la même édition, la première, publiée à Alcalá de Henares, en 1540, par Juan de Brocar.
\end{abstract}

Mots-clés: Glosa, Rodrigo de Valdepeñas, Jorge Manrique, Bayerische Staatsbibliothek, Hispanic Society of America, première édition, Juan de Brocar.

El artículo estudia dos ejemplares de la Glosa de Rodrigo de Valdepeñas (15051560) a las Coplas por la muerte de su padre de Jorge Manrique (1440-1479): el primero está guardado en la Bayerische Staatsbibliothek de Múnich, el segundo en la Biblioteca de la Hispanic Society of America de New York. Se demuestra que los dos son ejemplares de una misma edición, la primera, publicada en Alcalá de Henares, en el 1540, por Juan de Brocar.

Palabras claves: Glosa, Rodrigo de Valdepeñas, Jorge Manrique, Bayerische Staatsbibliothek, Hispanic Society of America, primera edición.

Don Rodrigo de Valdepeñas and the first edition of the "Glosa" in addition to Jorge Manrique’s "Coplas" (1540)

The article studies the "Glosa" composed by Rodrigo de Valdepeñas (1505-1560) to expound the "Coplas por la muerte de su padre" by Jorge Manrique (1440-1479). In this work, we will compare the copies of the work kept at the Bayerische Staatsbibliothek in Múnich to that of the Hispanic Society of America Library in New York and show that they are both samples of the same edition, the first one published in Alcalá de Henares by the printing press of Juan de Brocar in 1540.

Keywords: Glosa, Rodrigo de Valdepeñas, Jorge Manrique, Bayerische Staatsbibliothek, Hispanic Society of America, first edition. 

1 acido el 10 mayo de 1505, Rodrigo de Valdepeñas se matriculó en los hábito cartujano. A pesar de los escasos datos disponibles, se sabe que Rodrigo desempeńó el cargo de Visitador de la Provincia cartujana de Castilla (1552), así como de Prior en El Paular (1536-1545) y en la cartuxa de Granada (15451552). Después fue enviado al monasterio de Nuestra Señora de Las Cuevas (1552-1556), en Sevilla; luego a Cazalla (1558-1560) y, por último, a Jerez de la Frontera, donde murió el 6 de septiembre de $1560^{1}$. Esta carrera monástica se correspondió con una vivaz actividad intelectual, iniciada ya durante los años universitarios cuando, en consolación por la muerte de otro hijo, Rodrigo de Valdepeñas envió a su padre una versión manuscrita de la Glosa a las Coplas por la muerte de su padre del poeta castellano Jorge Manrique (1440-1479)².

Esta obra, que hubo de merecer estudios y profundización ${ }^{3}$, constituye lamentablemente el único testimonio conocido de su dilatada actividad literaria ${ }^{4}$.

1. Véase al respecto Eusebio Vasco y Gallego, Valdepeñeros ilustres. Apuntes biográficos, Valdepeñas, Imprenta de Casto Pérez, 1890-1895, págs. 81-85; Baltasar Cuartero y Huerta, Historia de la Cartuja de Santa Maria de las Cuevas, de Sevilla, y de su filial de Cazalla de la Sierra, Madrid, Real Academia de la Historia, 1950, págs. 406-407 y 424-430; Escritores cartujanos españoles, por un cartujo de Aula Dei e Ildefonso M. Gómez, M. B., Abadía de Monserrat, 1970, págs. 156-157; las introducciones al Libro del principio, fundación y prosecución de la Cartuja de Granada, trascripción del manuscrito, introducción e índices por Beatriz Esteban Muñecas; traducción de los textos latinos por Salvador Sandoval; fotografías y planta del estado actual de la Cartuja de Granada por Gerardo Cosa Orenes, Salzburg-Murcia, Institut füranglistik und amerikanistik Universität Salzburg, 2003 y Libro del prinçipio, fundaçion y proseçucion de la Cartuxa de Granada, edición y estudio de Francisco Miguel Torres Martín, Granada, Universidad de Granada, 2007.

2. En relación a las Glosas del poema de Manrique: Nellie E. Sánchez Arce, Las Glosas a las «Coplas» de Jorge Manrique, Madrid, Sancha, 1956; para la tradición textual véase Vicente Beltrán: «La trasmisión textual de las Coplas manriqueñas (1480-1540)», Incipit, 7 (1987), págs. 95-117 y Coplas que hizo Jorge Manrique a la muerte de su padre, Barcelona, Promociones y Publicaciones Universitarias, 1991. Para la edición filológica más moderna de las obras de Manrique: Jorge Manrique, Poesía, edición, estudio y notas de Vicenç Beltran, Madrid, Real Academia Española, 2013. Sobre la difusión de los textos manriqueńos: Manuel Herrera Vázquez, Las obras menores de Jorge Manrique: su transmisión y recepción en los siglos de Oro, Palencia, Institución Tello Téllez de Meneses CECL-CSIC, 2006 y Nancy F. Marino, Jorge Manrique's Coplas por la muerte de su padre. A History of the Poem and its Reception, New York, Tamesis, 2011. Para un análisis de la Glosa de Valdepeñas: Ana María Rodado Ruiz, «Literatura manchega hacia 1500: la glosa de Cartujano en su contexto», Cuadernos de estudios manchegos, 22 (1996), págs. 139-169.

3. Para la composición de la Glosa don Rodrigo utilizó otras obras: como el mismo autor escribe en la introducción a las Coplas XXVII-XXXV, que no tienen glosa, Las nueue coplas que siguen son todas de do [n] Iorge las quales ni el otro glosador tocol ni yo las entiendo glosar (Rodrigo de Valdepeñas, Glosa religiosa y muy christiana sobre las Coplas de don Iorge Manrrique, Alcalá de He ares, Juan de Brocar, 1540, a partir de ahora indicado como: R. de Valdepeñas, Glosa, 1540, h. C3r). En efecto, como ya ha indicado Beltran, la Glosa de Valdepeñas utiliza el cancionero de Ińigo de Mendoza (Vita Christi fecha por coplas, [Zamora, Centenera, 1483?]) y el texto de Alonso de Cervantes, Glosa famosisima sobre las coplas de don Jorge Manrrique, Lisboa, Valentin Fernández, 1501: véase V. Beltrán, La trasmisión textual, op. cit., pág. 113.

4. Huellas y noticias de su obra literaria se encuentran en el Prólogo a la primera edición, compuesto por el padre Bernardo Pérez, donde se lee que otras obras suyas de mas calidad se 
Acompañada de un prologo casero «y (como suelen ser las cosas de hijos a padres) no tan recatado quanto deurian los que han de peregrinar por el vulgo" ${ }^{5}$, la Glosa tuvo, en principio, una circulación manuscrita y exclusivamente familiar. Solo quince años más tarde, el padre Bernardo Pérez, vicario del monasterio de El Paular y conocedor del valor moral de los textos, se preocupó por recuperar la obra y se encargó de su impresión:

Del qual florido vergel [don Rodrigo], me parescio al p[re]se[n]te coger esta fresca rosa, o p[ar]a hablar claro, religiosa glosa (q[ue] tal no[m]bre me parescio ponelle) $\mathrm{p}$ [ar]a q[ue] salida en publico todos goze[n] de su olor. Engañarse ha quie[n] por esta obra quisiere juzgar la sciencia del auctor: harto es q[uien] en ella vera vn basta[n]te indicio de su mucha suficie[n]cia. Otras obras suyas de mas calidad se podria[n] sacar a luz, sino pareciese ostentacion. Y si yo p[ro]cure q[ue] saliesse esta fue co[n] temor $\mathrm{q}[\mathrm{ue}]$ por huir mucho la vanagloria: no cayessemos en neglige[n]cia ${ }^{6}$.

Según lo que el propio don Rodrigo escribe en la segunda edición, el autor solo se percató de la impresión cuando la obra ya estaba a la venta. Además, tuvo que defenderse de las acusaciones de vanagloria - por haber llevado los escritos a la imprenta-, pues, aunque Pérez actuó con cautela y evitó indicar el autor de la obra, parece que fue el impresor quien incorporó el nombre de Valdepeñas en el colophon del libro7:

hizo imprimir en verdad sin yo lo saber ni poder estoruar la impression: porque lo supe quando era publicada la obra/ y se vendia por los libreros: y dado que en nuestra casa ouo cuydado de encubrir mi nombre: el impressor al fin lo expresso ${ }^{8}$.

En efecto, como anota Valdepeñas en la segunda edición de la Glosa, la inoportuna revelación le comportó algunas molestias, dado que sus detractores consideraban ilícito que un religioso compusiese versos ${ }^{9}$ : en respuesta a una «murmuracio[n]» semejante, él recordó que ya san Ambrosio y san Próspero fueron autores de obras en verso, como también lo habían sido Job o David, y defendió que la bondad del texto debía depender de sus contenidos y no

podria[n] sacar a luz: R. de Valdepeñas, Glosa, 1540, op. cit., h. A5v. En la segunda edición el mismo Valdepeñas habla de disparates de mi liuiana juuentud y añade que el caso memorable y espantoso estaba entre otros mis papeles: Rodrigo de Valdepeñas, Glosa religiosa y muy christiana sobre las coplas de don George Manrrique. que comiença. Recuerde el alma dormida. Agora de nueuo segunda vez impressa, y pos su Autor corregida y emendada, añadido vn caso espantoso que passó en hecho de verdad que cuenta de metro el mesmo autor [Alcalá de Henares, Juan Brocar. c. 1560?] (a partir de ahora indicado como: R. de Valdepeñas, Glosa, 1560?) hh. A3r e A4r. Sánchez Arce plantea que también la composición presente en las ediciones sucesivas a la segunda, sobre un caso memorable que acaecio a una dama en la Francia, se podría atribuir a Valdepeñas: N. E. Sánchez Arce, Las Glosas a las "Coplas», op. cit., pág. 40. Además hay que tener en cuenta el Libro del prinçipio, sobre la historia de la casa cartujana de Granada, empezado por el mismo Rodrigo en el 1545 y ya señalado en la nota 1.

5. R. de Valdepeñas, Glosa, 1560?, op. cit., h. A2v.

6. R. de Valdepeñas, Glosa, 1540, op. cit., h. A5v.

7. Ibid.

8. R. de Valdepeñas, Glosa, 1560?, op. cit., h. A3r.

9. R. de Valdepeñas, Glosa, 1560?, op. cit., h. A2r. 
del género literario empleado ${ }^{10}$. Por consiguiente, aceptó la oferta de Juan de Brocar de realizar una nueva edición de la obra, que permitió a don Rodrigo modificar algunas composiciones y corregir ciertos errores: «porque con ello se da lugar ala presente desculpa. Y porque en esta impressio[n] aya algo de nueuo: allende de emendar por mi mano/ lo que en la otra impression halle defectuoso/ o corrupto» ${ }^{11}$. Así, en esta segunda impresión, datada por los bibliógrafos en 1560 aunque carente, en realidad, de pie de imprenta, el autor no se limitó a incorporar su Prólogo; también depuró los textos, eliminó las introducciones y composiciones en su honor, y añadió un caso memorable y espantoso ${ }^{12}$. El caso cuenta la historia de un caballero tan soberbio que, por haber decidido mantenerse al margen de la fe cristiana incluso en el momento de su muerte, mereció el castigo de Dios: como la Glosa, también el caso tiene una evidente finalidad moral y didascálica ${ }^{13}$.

A partir de esta segunda edición, la obra tuvo un gran éxito editorial. Según los estudios de Antonio Pérez y Gómez y Manuel Carrión Gutiez, la Glosa del Valdepeñas fue, junto a la de Alonso de Cervantes, la más popular entre aquellas dedicadas a las Coplas de Manrique. De hecho, solo en el siglo XVI ya se cuentan catorce ediciones ${ }^{14}$.

\section{La primera edición impresa de la Glosa. Descripción y eJemplares}

A pesar del éxito de la obra, durante mucho tiempo el problema sobre la datación de la primera edición del texto del Valdepeñas ha permanecido abierto. Basándose en un profundo análisis de las diferentes Glosas a las Coplas de Manrique, Pérez y Gómez propuso que la primera impresión del comento de Valdepeñas se había completado en el taller complutense de Juan de Brocar antes de $1541^{15}$. Aceptada por los investigadores, esta hipótesis no pudo ser comprobada porque no se conocía ningún ejemplar con las oportunas notas tipográficas.

10. Id., h. A3v.

11. Id., h. A4r.

12. Para las diferencias entre las dos ediciones se vea más adelante la Comparación entre la estructura de la primera y de la segunda edición y el Cotejo de los textos entre primera y segunda edición.

13. Sobre el Caso, véase María Sánchez-Pérez, «La refundación de obras en el Siglo de oro: el ejemplo de la literatura popular impresa", Lectura y signo. Revista de literatura, 8(2013), págs. 9-34.

14. Antonio Pérez y Gómez, Glosas a las Coplas de Jorge Manrique, Cieza, La fonte que mana y corre, 1961-1963, 6 vols.: particularmente, puede verse el capítulo sobre las Noticias bibliográficas, en el sexto tomo; Manuel Carrión Gutiez, Bibliografía de Jorge Manrique: homenaje al poeta en el V centenario de su muerte, Palencia, Diputación Provincial, 1979. Un cuadro dedicado a las ediciones de las glosas se puede encontrar también en José J. Labrador, C. Ángel Zorita, Ralph A. DiFranco, "Cuarenta y dos, no cuarenta coplas en la famosa elegía manriqueña», Boletín de la Biblioteca de Menéndez Pelayo, 51 (1985), págs. 37-95.

15. A. Pérez y Gómez, Glosas a las Coplas de Jorge Manrique, VI, Noticias bibliográficas, op. cit., n 15; M. Carrión Gutiez, Bibliografía de Jorge Manrique, op. cit., nº 126. 
Gracias a los modernos catálogos digitales de las bibliotecas europeas, ahora se puede confirmar la hipótesis del ilustre investigador y avanzar nuevas consideraciones a partir del estudio del ejemplar guardado en la Bayerische Staatsbibliothek de Múnich ${ }^{16}$. El libro, intitulado Glosa religiosa y muy christiana sobre las Coplas de don Iorge Manrrique que comiença. Recuerde el alma dormida. Agora de nueuo compuesta por vn reuerendo padre Monje Cartuxo, presenta una elegante encuadernación y procede de la biblioteca de Bartholomäus May (ca. 1515-1576) ${ }^{17}$. Bibliófilo y hábil hombre de negocios, Bartholomäus trabajó para la compañía financiera y comercial de los Welser; su carrera se desarrolló entre Habsburgo y España adonde, en los años cuarenta del siglo XVI, se mudó para seguir las actividades de la sociedad. Y fue durante su temporada ibérica cuando el bibliófilo alemán pudo comprar valiosos libros que acabaron formando el vasto fondo español de su biblioteca. La colección, así constituida, fue donada por los herederos a la ciudad de Habsburgo y, finalmente, acabó en la Staatsbibliothek en el 1868. Si volvemos al estudio del volumen, y confiamos en las informaciones del colophon, este fue impreso en Alcalá de Henares en 1540, en la oficina tipográfica de Juan de Brocar, después de que el vicario general de Toledo, Pedro de la Gasca, concedió la oportuna licencia ${ }^{18}$. El libro se abre con el Prologo del autor y con la Carta consolatoria en la que Bernardo Pérez reconoce haber editado la edición al margen de la voluntad de don Rodrigo; siguen la Breue annotacion sobre la interpretación de algunas indicaciones presentes en el texto, las Coplas glosadas, la composición En loor del glosador y el colophon.

Esta primera descripción permite subrayar cómo el volumen muniqués examinado resulta idéntico al ejemplar de la Glosa recogido, en New York,

16. Múnich, Bayerische Staatsbibliothek, 4 P.o.hisp. 50 n. El ejemplar (cubierta: mm. 210x143; hojas: $\mathrm{mm}$. 205x140) presenta un plato delantero decorado, con referencias al autor y al posesor del volumen en caracteres dorados: DE DO[N] || IORGE || MANRI || QVE e BART || OLO || ME || MAY. Una reproducción digital puede consultarse en la página web de la Biblioteca: https://opacplus.bsb-muenchen.de/search?oclcno $=165574204 \& \mathrm{db}=100$ consultado el 20 mayo 2018. Por las informaciones facilitadas, mi gratitud va al doctor Klaus Kempf, ex director de la Bayerische Staatsbibliothek, y a la doctora Claudia Bubenik, responsable del sector Alte und Seltene Drucke. También se agradecen Jürgen Ritter y Cornelius Lochschmidt, del departamento Abteilung Benutzungsdienste Dokumentlieferung Altes Buch de la misma Biblioteca, por el envío de las imágenes.

17. Sobre Bartholomäus May y su biblioteca véase Irmgard Bezzel, «Bartholomäus May (ca. 1515-1576) aus Bern, ein Sammler spanischer Drucke», Iberoromania, 1 (1969), págs. 235243; Wolfgang Reinahard, Augsburger Eliten des 16. Jahrhunderts. Prosopographie wirtschaftlicher und politischer Führungsgruppen 1500-1620, Berlin, Akademie, 1996, págs. 526-527.

18. Pedro de la Gasca (1493-1567) fue una destacada personalidad de la monarquía espańola: estudiante de teología y derecho en los ateneos complutense y salmantino, fue miembro de la Inquisición, vicario de Alcalá y Toledo, obispo de Palencia y Sigüenza. Además de las dignidades eclesiásticas, don Pedro desempeñó cargos políticos en España y en el Nuevo Mundo. La bibliografía sobre De La Gasca es amplia: aquí será suficiente recordar Teodoro Hampe Martínez, «Don Pedro de la Gasca y la proyección del mundo universitario salmantino en el siglo XVI», Mélanges de la Casa de Velázquez, 22 (1986) págs. 171-196. Por la legislación sobre el libro en la España moderna véase Fermín De Los Reyes Gómez, El libro en España y América. Legislación y censura (siglos XV-XVIII), Madrid, Arcolibros, 2000, 2 vols. 
por la Hispanic Society of America (HSA) ${ }^{19}$. Este libro, siempre atribuible al taller de Juan de Brocar y datado por Julián Martín Abad alrededor de $1540^{20}$, no presenta colophon y perteneció a la gran biblioteca sevillana del marqués de Jerez de los Caballeros; posteriormente, en 1902, fue adquirido por Archer Milton Huntington, fundador del $\mathrm{HSA}^{21}$. En comparación con el volumen alemán, este neoyorquino carece de la hoja C8 que, en la opinión de Pérez y Gómez, podía estar en blanco; además, según la valiosa descripción de Martín Abad, el ejemplar se caracterizaría por un error de signatura en la hoja A4, signada como A3. En realidad, conforme al análisis de una reproducción digital facilitada por la HSA, puede afirmarse que el ejemplar americano no posee ningún error de signatura. Así, si partimos de estos datos y si suponemos que la última hoja ausente no estuviese en blanco sino que contuviese el colophon, puede plantearse que el presente volumen de la Glosa constituye otro ejemplar de la primera edición de la obra de Valdepeñas ${ }^{22}$.

A partir de estas noticias, es posible afirmar que los dos ejemplares remiten a la editio princeps de la Glosa, impresa en Alcalá de Henares, por Juan de Brocar, en $1540^{23}$. Tras esta, aparecieron una segunda edición, publicada en la ciudad complutense $\left(1560\right.$ ?) ${ }^{24}$, un pliego poético sin notas tipográficas (datado entre

19. New York, Hispanic Society of America, PQ 6412 .M6 V35 [bet. 1540-1552?]. El ejemplar, sin encuadernación, mide mm. 186x136. Se agradece al doctor John O’Neill, Curator of Manuscripts and Rare Books de la HSA, por haber facilitado una reproducción del libro y por la detallada comprobación del mismo.

20. Julián Martín Abad, La imprenta en Alcalá de Henares: 1502-1600, Madrid, ArcoLibros, 1991, $\mathrm{n}^{\circ}$ 316: "Glosa religiosa y muy christiana sobre las Coplas de don Iorge Manrrique que comiença Recuerde el alma dormida. Agora de nueuo compuesta por un reuerendo padre Monje Cartuxo [Alcalá de Henares. En casa de Juan de Brocar. c. 1540?]». Otras descripciones del ejemplar en A. Pérez y Gómez, Glosas a las Coplas de Jorge Manrique, VI, Noticias bibliográficas, op. cit., $\mathrm{n}^{\circ} 16$ y Printed books (1468-1700) in the Hispanic Society of America, a listing by Clara Louisa Penney, New York, The Hispanic Society of America, 1965, pág. 332.

21. Para la historia de la biblioteca del marqués de Jerez de los Caballeros: John O’Neill, «Don Manuel Pérez de Guzmán, Marqués de Jerez de los Caballeros, Bibliófilo y Académico», Boletín de la Real academia Sevillana de Buenas Letras: Minervae baeticae, 37 (2009), págs. 331-344.

22. El cotejo entre los dos ejemplares refuerza la hipótesis. Si la propuesta es correcta, las entradas $\mathrm{n}^{\circ} 15 \mathrm{y} \mathrm{n}^{\circ} 16$ de Pérez y Gómez habrían de agruparse en una sola: A. Pérez y Gómez, Glosas a las Coplas de Jorge Manrique, VI, Noticias bibliográficas, op. cit:; lo mismo para las entradas n ${ }^{\circ} 126$ y n $^{\circ} 127$ en M. Carrión Gutiez, Bibliografía de Jorge Manrique, op. cit.

23. R. de Valdepeñas, Glosa, 1540, op. cit. (J. Martín Abad, La imprenta, op. cit., n 316; M. Carrión Gutiez, Bibliografia de Jorge Manrique, op. cit., $\mathrm{n}^{\circ}$ 126; Printed books, op. cit., pág. 332; A. Pérez y Gómez, Glosas a las Coplas de Jorge Manrique, VI, Noticias bibliográficas, op. cit., $\left.\mathrm{n}^{\circ} 15 \mathrm{y} \mathrm{n}^{\circ} 16\right)$.

24. R. de Valdepeñas, Glosa, 1560?, op. cit. (J. Martín Abad, La imprenta, op. cit., n 549; A. Pérez y Gómez, Glosas a las Coplas de Jorge Manrique, VI, Noticias bibliográficas, op. cit., $\mathrm{n}^{\circ}$ 17; M. Carrión Gutiez, Bibliografía de Jorge Manrique, op. cit., $\mathrm{n}^{\circ}$ 128). Una reproducción del ejemplar, guardado en la Biblioteca Nacional de España (R. 10385), puede encontrarse en el primer tomo del estudio de Pérez y Gómez y, ahora, en la Biblioteca digital Hispánica: http:// bdh.bne.es/bnesearch/detalle/bdh0000051611 (consultado el 20 mayo 2018). 
1555 y 1560 $)^{25}$ y después, en orden cronológico, las impresiones de Alcalá $(1564)^{26}$, Cagliari $(1568)^{27}$, Alcalá $\left(1570^{28}, 1571^{29}\right)$, Sevilla $(1575)^{30}$, Alcalá

25. Glosa religiosa y muy cristiana, sobre las coplas de don Jeorge Manrique, que comiença. Recuerde el alma dormida. Ahora nueuamente por su autor corregida y enmendada [sl. sa.] (Antonio Rodríguez Moñino, Nuevo diccionario bibliográfico de pliegos sueltos poéticos (siglo XVI), edición corregida y actualizada por Arthur L-F. Askins y Víctor Infantes, Madrid, Editorial Castalia, 1997, n 619.8; A. Pérez y Gómez, Glosas a las Coplas de Jorge Manrique, VI, Noticias bibliográficas, op. cit., n 18; M. Carrión Gutiez, Bibliografía de Jorge Manrique, op. cit., $\mathrm{n}^{\circ}$ 129). Fernández Valladares plantea que el ejemplar se imprimió en Burgos por los herederos de Juan de Junta o de Felipe de Junta entre 1555 y 1560: Mercedes Fernández Valladares, «Indicios y evidencias para la asignación tipobibliográfica de los pliegos sueltos burgaleses del siglo XVI», en La literatura popular impresa en España y en la América Colonial: formas y temas, géneros, funciones, difusión, historia y teoría, dirigido por P. M. Cátedra, edición al cuidado de Eva Belén Carro Carbajal, Laura Mier, Laura Puerto Moro, María Sánchez Pérez, Salamanca, Semyr, 2005, págs. 437-475: 470.

26. Las coplas de Don Jorge Manrique. Con una glosa muy deuota y christiana de un religioso de la cartuxa. Va juntamente un caso memorable de la conversion de una dama. Con las cartas en refranes de Blasco de Garay. Con un Diálogo entre el amor y un caballero viejo. Compuesto por Rodrigo Cota, Alcalá de Henares, Francisco de Cormellas \& Pedro de Robles, 1564 (J. Martín Abad, La imprenta, op. cit., n 611; A. Pérez y Gómez, Glosas a las Coplas de Jorge Manrique, VI, Noticias bibliográficas, op. cit., $\mathrm{n}^{\circ}$ 19; M. Carrión Gutiez, Bibliografía de Jorge Manrique, op. cit., $\left.\mathrm{n}^{\circ} 130\right)$.

27. Glosa religiosa y mvy christiana sobre las Coplas de Don Iorge Manrrique. Que comiença, Recuerde el alma dormida. Compuesta por un Reuerendo Padre Monje Carthuxo, Cagliari, Nicolò Canyelles, 1568. Sobre esta edición véase: Giuseppe Seche, «L'edizione sarda della Glosa di don Rodrigo de Valdepeñas alle Coplas di Jorge Manrique», La Bibliofilia, 117/1 (2015), págs. 59-79.

28. Las coplas de don Iorge Manrique con una glosa muy deuota y christiana, de un religioso de la Cartuxa. Va juntamente un caso memorable de la conuersion de una dama. Assi mismo, va agora nueuamente añadia la glosa de Mingo Reuulgo. Y las cartas en refranes de Blasco de Garay... Con un dialogo entre el amor y un cauallero viejo compuesto por Rodrigo Cota, Alcalá de Henares, Andrés de Angulo, 1570 (J. Martín Abad, La imprenta, op. cit., n 752; A. Pérez y Gómez, Glosas a las Coplas de Jorge Manrique, VI, Noticias bibliográficas, op. cit., n² 20; M. Carrión Gutiez, Bibliografia de Jorge Manrique, op. cit., $\mathrm{n}^{\circ} 132$ ).

29. Coplas... con una glosa muy devota y christiana, de un religioso de la Cartuxa. Va juntamente un caso memorable de la conversión de una Dama. Assi mismo las cartas en refranes de Blasco de Garay... Con un diálogo entre el amor y un cavallero viejo. Compuesto por Rodrigo Cota, Alcalá de Henares, Juan Gracián, 1571 (J. Martín Abad, La imprenta, op. cit., nº 767).

30. Coplas de don Jorge Manrique. Con vna glosa muy deuota y christiana de vn religioso de la Cartuxa. Va juntamente un caso memorable de la conuersion de vna dama. Assi mismo las cartas en refranes de Blasco de Garay racionedo de la sancta yglesia de Toledo, con vn dialogo entre el amor y vn cauallero viejo compuesto por Rodrigo Cota, Sevilla, Alonso Picardo, 1575 (A. Pérez y Gómez, Glosas a las Coplas de Jorge Manrique, VI, Noticias bibliográficas, op. cit., $\mathrm{n}^{\circ}$ 21; M. Carrión Gutiez, Bibliografía de Jorge Manrique, op. cit., n 133). En su Prólogo a las Coplas publicadas en Madrid en 1779, Antonio de Sancha afirma conocer otra edición sevillana impresa en 1577: «La primera impresión de esta glosa que hemos visto, se hizo en Sevilla en casa de Alonso Picardo, impresor de libros, año M. D. LXXVII. en 12. con el siguiente título: Coplas de Jorge Manrique, con una Glosa muy devota y Christiana de un Religioso Cartuja. Va juntamente un caso memorable de la conversion de una dama. Assimismo las Cartas de refranes de Blasco de Garay, Racionero de la Santa Iglesia de Toledo, con un Dialogo entre el Amor y un Caballero, compuesto por Rodrigo Cota» (en Coplas de Don Jorge Manrique, hechas a la muerte de su padre Don Rodrigo Manrique, con las glosas en verso a ellas de Juan de Guzmán del P. don Rodrigo de 
$(1581)^{31}$, Medina del Campo $(1582)^{32}$, Huesca $(1584)^{33}$, Alcalá $(1588)^{34}$, Valencia $(1589)^{35}$ y Madrid $(1598)^{36}$. No se conocen ejemplares de las ediciones

Valdepeñas, monge Cartujo, del proto-notario Luis Perez, y del licdo. Alonso Cervantes, Madrid, Antonio de Sancha, 1779, págs. XI-XII). Además, Sancha, fundándose en la datación de la licencia (12 mayo 1572), propone otra impresión anterior. Por su parte, Francisco Escudero rechaza la hipótesis y expresa dudas también sobre la edición de 1577: Francisco Escudero y Perosso, Tipografia hispalense, Madrid, Sucesores de Rivadeneyra, 1894, n 693. Comparten la misma idea Carrión e y Pérez y Gómez: A. Pérez y Gómez, Glosas a las Coplas de Jorge Manrique, VI, Noticias bibliográficas, op. cit., $\mathrm{n}^{\circ} 68$ e M. Carrión Gutiez, Bibliografía de Jorge Manrique, op. cit., $\mathrm{n}^{\circ} 133$.

31. Las coplas de don Jorge Manrique con una glosa muy devota y christiana, de un religioso de la Cartuxa. Va juntamente un caso memorable de la conversión de una dama. Assimismo, va aora nuevamente añadida la Glosa de Mingo Revulgo. Y las cartas en refranes de Blasco Garay, racionero de la santa yglesia de Toledo. Con un diálogo entre el amor y un cavallero viejo. Compuesto por Rodrigo Cota, Alcalá de Henares, Querino Gerardo, 1581 (J. Martín Abad, La imprenta, op. cit., $n^{\circ}$ 910; A. Pérez y Gómez, Glosas a las Coplas de Jorge Manrique, VI, Noticias bibliográficas, op. cit., $\mathrm{n}^{\circ}$ 22; M. Carrión Gutiez, Bibliografía de Jorge Manrique, op. cit., $\left.\mathrm{n}^{\circ} 134\right)$.

32. Coplas de Don Jorge Manrique con vna glosa muy deuota y Christiana, de vn religioso de la Cartuxa. Va juntamente vn caso memorable de la conuersion de vna dama. Assi mismo las cartas en refranes de Blasco de Garay racionero de la sancta Yglesia de Toledo. Con vn Dialogo entre el amor y vn cauallero viejo. Compuesto por Rodrigo Cota, Medina del Campo, Francisco del Canto, 1582 (A. Pérez y Gómez, Glosas a las Coplas de Jorge Manrique, VI, Noticias bibliográficas, op. cit., 23; M. Carrión Gutiez, Bibliografía de Jorge Manrique, op. cit., $\left.\mathrm{n}^{\circ} 135\right)$.

33. Coplas de don Iorge Manrique con vna glosa muy deuota y christiana, de vn religioso de la Cartuxa. Van añadidas las coplas de Mingo Reuulgo glosadas por Hernando del Pulgar. Intamente va vn caso memorable, de la conuersion de vna dama. Assi mismo van las cartas, en refranes de Blasco de Garay, racionero de la sancta Iglesia de Toledo. Con vn Dialogo entre el amor, y vn cayallero viejo compuesto por Rodrigo Cota, Huesca, Juan Pérez de Valdivielso, 1584 (A. Pérez y Gómez, Glosas a las Coplas de Jorge Manrique, VI, Noticias bibliográficas, op. cit., n² 24; M. Carrión Gutiez, Bibliografia de Jorge Manrique, op. cit., $\mathrm{n}^{\circ} 136$ ).

34. Las coplas de don Iorge Manrique con vna glossa muy deuota y christiana, de vn religioso de la Cartuxa. Va juntamente vn caso memorable de la conuersion de vna dama. Assi mismo, va aora nueuamete añadida la glosa de Mingo Reuulgo. Y las cartas en refranes de Blasco de Garay, racionero de la santa yglesia de Toledo. Con vn dialogo entre el amor y vn cauallero viejo. Compuesto por Rodrigo Cota, Alcalá de Henares, Hernán Ramírez, 1588 (J. Martín Abad, La imprenta, op. cit., $\mathrm{n}^{\circ}$ 1011; A. Pérez y Gómez, Glosas a las Coplas de Jorge Manrique, VI, Noticias bibliográficas, op. cit., $\mathrm{n}^{\circ}$ 25; M. Carrión Gutiez, Bibliografía de Jorge Manrique, op. cit., $\left.\mathrm{n}^{\circ} 137\right)$.

35. Coplas de Don Jorge Manrique. Con vna glosa muy devota y christiana, de vn religioso de la Cartuxa. Va juntamente vn caso memorable de la conversion de vna dama. Assi mismo, va aora nueuamente añadida la glosa de Mingo Reulgo. Y las cartas en refranes de Blasco de Garay... Con un dialago entre el amor y un cauallero uiejo. Compuesto por Rodrigo Cota, Valencia, Herederos de Juan Navarro, 1589 (Margarita Bosch Cantallops, Contribución al estudio de la imprenta en Valencia en el siglo XVI, Madrid, Universidad Complutense, 1989, n 816).

36. Las coplas de Don Iorge Manrique. Con vna glossa muy deuota y Christiana de vn religioso de la Cartuxa. Va iuntamente vn caso memorable de la conuersion de vna dama. Assi mismo va aora nueuamente añadida la glossa de Mingo Reuulgo. y las cartas en refranes de Blasco Garay racionero de la santa Yglesia de Toledo. Con vn dialogo entre el amor y vn cauallero vieio compuesto por Rodrigo Cota, Madrid, Luis Sánchez, 1598 (Yolanda Clemente San Román, Tipobibliografía madrileña: la imprenta en Madrid en el siglo XVI (1566-1600), Kassel, Reichenberger, 1998 $\mathrm{n}^{\circ}$ 793; A. Pérez y Gómez, Glosas a las Coplas de Jorge Manrique, VI, Noticias bibliográficas, op. cit., $\mathrm{n}^{\circ}$ 25; M. Carrión Gutiez, Bibliografía de Jorge Manrique, op. cit., $\mathrm{n}^{\circ}$ 139). 
de Medina del Campo (1569) y de Valencia (1589) ${ }^{37}$, pero deben recordarse los textos de las Coplas que el padre Valdepeñas, cuando fue prior, hizo grabar en el monasterio de El Paular para animar la fe de los hermanos ${ }^{38}$.

\section{DESCRIPCIÓN ANALÍTICA DE LA EDICIÓN}

Portada (Fig. 1 y 2): [Grabado (mm. 130x90) enmarcado por dos columnas laterales y un friso, a su vez rodeado por adornos tipográficos en rojo. En la parte alta del grabado está la Virgen con un niño y un monje orante; en la parte inferior una dama ofrece la mano a un niño, mientras un caballero sostiene la espada desenvainada. Entre las dos partes hay una cinta con la leyenda: CONTRA FVRIA DE FORTVNA NO AY COŌSEIO NI SCIENÇIA SINO GOVIERNA PRVDENÇIA. Otra cinta con leyenda en rojo reza: Nuestra Señora del Paular]. || [En rojo entre dos hojas aldinas:] Glosa religiosa y muy christiana sobre las || Coplas de don [En negro:] Iorge Manrrique [En rojo:] que/ comiença. [En negro:] Recuerde el alma dormida. || [En rojo:] Agora de nueuo compuesta por vn reuerendo padre Monje Cartuxo.

hh. A2r-A4r: Prologo del autor. hh. A4r-A5v: Carta consolatoria de don Bernardo Pérez, vicario de El Paular. h. A5v: Aviso sobre las anotaciones presentes en el texto. hh. A6r-C7r: Coplas y glosas. h. C7v: Composición en honor de Valdepeñas. h. C8r: Colophon (Fig. 3).

In $4^{\circ}, \mathrm{A}-\mathrm{D} 8 ; 48$ hojas. A1v y C8v en blanco.

Iniciales grabadas in $\mathrm{A} 2 \mathrm{r}$ y $\mathrm{A} 4 \mathrm{v}$.

EJEMPLARES

Múnich. Bayerische Staatsbibliothek, 4 P.o.hisp. 50 n.

New York. Hispanic Society of America, PQ 6412 .M6 V35 [bet. 15401552?].

37. A. Pérez y Gómez, Glosas a las Coplas de Jorge Manrique, VI, Noticias bibliográficas, op. cit., $\mathrm{n}^{\circ} 67 \mathrm{y} \mathrm{n}^{\circ} 69$.

38. Aunque estos grabados se pueden leer solo parcialmente y con dificultad (en la actualidad, las dos inscripciones conservadas están cubiertas por los cuadros de Vincenzo Carducci), en el siglo pasado los versos fueron transcritos por Baltasar Cuartero y Huerta. Véase B. Cuartero y Huerta, Historia de la Cartuja, op. cit., págs. 424-430, donde el autor escribe que los textos estarían en el apéndice IV de su trabajo, todavía inédito, titulado: La Real Cartuja de Santa María del Paular. Su Historia y descripción. Por lo que respecta a la memoria del padre Valdepeñas en el monasterio de El Paular, se puede tener en cuenta que en el inventario de la biblioteca, datado en 1821, no se encuentra ninguna noticia sobre la presencia de sus obras: María Jesús Bielza Díaz-Caneja, "El monasterio de Santa María de El Paular: su biblioteca y su archivo», Cuadernos para Investigación de la Literatura hispánica, 17 (1993), págs. 187-332. 


\section{Comparación ENTRE LA ESTRUCTURA DE LA PRIMERA Y}

DE LA SEGUNDA EDICIÓN

En la siguiente tabla se registran las diferencias encontradas durante la comparación entre la estructura de las dos ediciones, la primera de $1540(I)$ y la segunda datada en $1560(I I)$.

\begin{tabular}{|c|c|}
\hline I (Alcalá, 1540) & II (Alcalá, 1560?) \\
\hline $\begin{array}{l}\text { h. A1r, título en la portada: } \\
\text { Glosa religiosa y muy christiana sobre } \\
\text { las II Coplas de don Iorge Manrrique } \\
\text { que/ comiença. Recuerde el alma } \\
\text { dormida. II Agora de nueuo compuesta } \\
\text { por vn reuerendo padre Monje Cartuxo. }\end{array}$ & $\begin{array}{l}\text { h. A1r, título en la portada: } \\
\text { I Glosa religiosa y muy christiana } \\
\text { sobre II las coplas de don George } \\
\text { Manrrique. q[ue] comie[n] \| ça. } \\
\text { Recuerde el alma dormida. Agora de } \\
\text { nueuo II segunda vez impressa, y por } \\
\text { su Autor corregida y \| eme[n]dada, } \\
\text { añadido vn caso espa[n]toso q[ue] } \\
\text { passo en he } \| \text { cho de verdad q[ue] } \\
\text { cue[n]ta de metro el mesmo autor. }\end{array}$ \\
\hline $\begin{array}{l}\text { hh. A2r-A4r, prólogo del autor: } \\
\text { | Prologo del auctor en el qual \| } \\
\text { endereça la obra a su padre co[n] } \| \\
\text { solandole de ciertos casos } \| \text { desastrados } \\
\text { que le aui= } \| \text { an acaescido. }\end{array}$ & $\begin{array}{l}\text { hh. A1v-A4v, prólogo del autor: } \\
\text { I Prologo del Autor en que \| de la } \\
\text { passada impression se excusa: y la } \\
\text { presen= } \| \text { te al lector endereça } \\
\text { añadiendo a la obra \| vn caso } \\
\text { memorable y espantoso que \| } \\
\text { contescio en hecho de verdad. \| para } \\
\text { escarmiento y auiso } \| \text { dlos lectores, } \\
\text { special= } \| \text { mente los obsti= } \| \text { nados } \\
\text { que } \| \text { no quie } \| \text { ren, } \| \text { o } \| \text { diffie } \| \text { ren } \\
\text { emen= } \| \text { dar se. }\end{array}$ \\
\hline $\begin{array}{l}\text { hh. A4r-A5v, carta consolatoria: } \\
\text { | Carta co[n]solatoria del religio= } \| \text { so } \\
\text { y deuoto padre fray Bernardo Perez } \\
\text { Vicario de la casa \| del Paular de la } \\
\text { orden de Carthuxa/ por cuyo mandado } \\
\text { || se imprimo la presente obra. Al muy } \\
\text { noble y magni= } \| \text { fico señor el señor } \\
\text { Diego de Valdepeñas Regidor } \| \text { de } \\
\text { ciudad real a quien fue dirigida la } \\
\text { presente o= } \| \text { bra co[n]sola[n]dole de la } \\
\text { muerte de vn hijo suyo. }\end{array}$ & - \\
\hline $\begin{array}{l}\text { h. A5v, aviso: } \\
\text { ף Breue annotacion del auctor para que } \\
\text { la obra I| mejor se entienda. }\end{array}$ & - \\
\hline
\end{tabular}




\begin{tabular}{|c|c|}
\hline I (Alcalá, 1540) & II (Alcalá, 1560?) \\
\hline $\begin{array}{l}\text { hh. A6r-C7r, Coplas y Glosa. } \\
\text { h. C3r-v: Coplas sin glosa. }\end{array}$ & $\begin{array}{l}\text { hh. A5r-C6r: Coplas y Glosa. } \\
\text { h. C2r-v: Coplas sin glosa. }\end{array}$ \\
\hline $\begin{array}{l}\text { h. C7v, composición: } \\
\text { ๆ En loor del glosador. }\end{array}$ & - \\
\hline- & $\begin{array}{l}\text { hh. [ ]1r-[ ]4v: } \\
\text { T Caso memorable y espa[n]toso que } \\
\text { I| acontescio en hecho de verdad: para } \\
\text { auiso y } \| \text { escarmiento delos } \\
\text { obstinados que no || quieren/o differen } \\
\text { conuertir se. }\end{array}$ \\
\hline 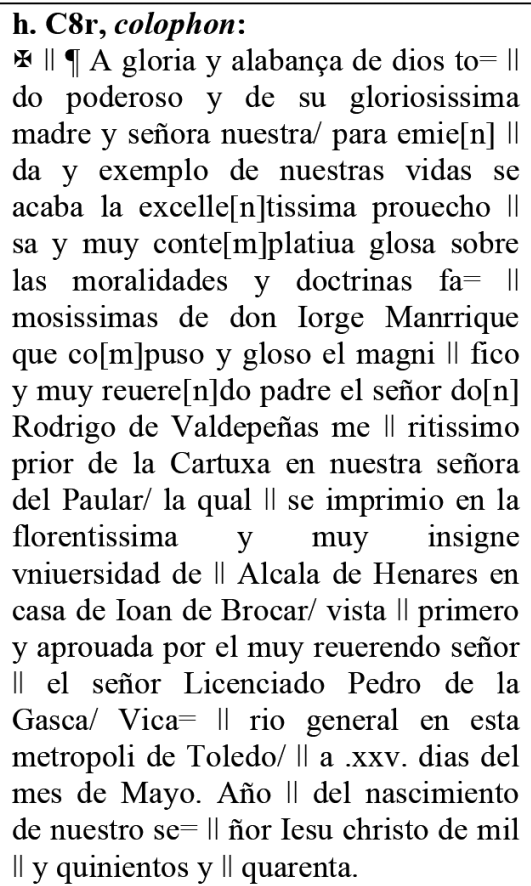 & - \\
\hline
\end{tabular}




\section{COTEJO DE LOS TEXTOS ENTRE PRIMERA Y SEGUNDA EDICIÓN}

Si prescindimos de pequeñas diferencias, muchas de ellas debidas a la voluntad del tipógrafo de abreviar palabras, a problemas de geminación, de puntuación, titulación o de numeración de las Coplas, las principales variaciones que el autor introdujo en la segunda edición (II) con respecto a la primera $(I)$ se recogen a continuación:

\section{Glosa a la Copla II}

Primera columna, vv. 17-18

I: mas primeros y te $[\mathrm{m}]$ pranos $\|$ se fenescen

II: mas primeros y tempranos $\|$ se acaescen

\section{Glosa a la Copla IV}

Segunda columna, vv. 13-18

I: Al dulce y sancto cordero $\|$ en quien no vuo fallacia || ni error || hijo de dios verdadero \| suplico me de su gracia $\| y$ fauor

II: Al dulce y sancto cordero $\|$ en quien maldad o fallacia || no es estable || hijo de dios verdadero || supplico me de su gracia \| fauorable

\section{Glosa a la Copla V}

Primera columna, v. 4

I: jamas holgura $\|$ ni tiene jamas reposo

II: jamas holgura \| ni puede tener reposo

\section{Glosa a la Copla VI}

Primera columna, v. 1

I: Alguna disfamia o mal

II: Alguna disfama o mal

Primera columna, v. 13

I: N[uestr] ras obras maldigamos

II: Nuestros hechos maldigamos

\section{Glosa a la Copla VII}

Primera columna, v. 17

I: del hediondo manjar

II: deste podrido manjar

\section{Glosa a la Copla XI}

Primera columna, v. 3

I: $y$ no estable

II: $y$ no es estable

\section{Glosa a la Copla XII}

Segunda columna, vv. 20-21

I: pues los vicios en q[ue] estamos \| son bestiales

II: pues los vicios en q[ue] estamos \| son celestiales

\section{Glosa a la Copla XIII}

Primera columna, v. 1

I: Mas lo q[ue] mas me hostiga

II: Y lo que mas me hostiga

\section{Glosa a la Copla XV}

Primera columna, vv. 20-21

I : $y$ a los cesares tan primos $\|$ en victorias

II: pues ta[n] breues conoscimos $\|$ sus memorias

Glosa a la Copla XVI

Segunda columna, v. 13

I: La apostura y la lindeza

II: La postura y la lindeza

\section{Glosa a la Copla XVII}

Segunda columna, v. 3

I: que mostrauas

II: que mostrauan?

Segunda columna, v. 6

I: en que estauds

II: en que estauan?

\section{Glosa a la Copla XX}

Primera columna, v. 7

I: viendo a rey tan eminente

II: viendo a rey tan eminnote

Glosa a la Copla XXI

Segunda columna, vv. 5-6

I: arrojar por las varandas $\|$ al vizconde de altamira

II: arrojar por las uara[n]das $\|$ al que dizen de viuero

Glosa a la Copla XXIV

Primera columna, v. 5

$\mathrm{I}:$ ante que nos engendrassen

II: que a[n] te $q[\mathrm{ue}]$ nos engre [n] dassen 
Introdución a las Coplas no glosadas (XXVII-XXXV)

I, h. C3r: Las nueue coplas que se siguen \| son todas de do[n] Iorge las quales ni el otro glosador tocol ni yo las || entiendo glosar: por no confundir su continuada y sabrosa sentencia. $\| Y$ por que a penas se podria sacar mucho fructo de su glosa: con ga $=\|$ star se en tocar historias que son fuera del proposito de nuestro pro $=\|$ cesso. Bien caeran los discretos en lo que digo. Y por que se gastan $\|$ en alabar al maestre: $y$ tengo temor de mi insufficiencia no suba a lo \|I increyble: $o$ baxelo tanbien ensalçado. Las coplas son estas

II, h. C2r: Las nueue coplas que se sigue [n] || son todas de don Iorge: las quales ni el otro glosador tocol ni yo || las entiendo glosar por no co[n] fundir su continuada y sabrosa sente[n] \|| cia. $Y$ por que a penas se podria sacar mucho fructo de su glosa: || con gastar se en tocar historias que son fuera del proposito de nue $=\|$ stro processo.
$Y$ porque se gastan en alabar al maestre. $y$ tengo $t e=\|$ mor de mi insufficiencia no suba a lo increyble: o hare lo tambien || ensalçado. Las coplas son estas.

\section{Glosa a la Copla XI}

Primera columna, v. 13

I: ya estamos junto a la paga

II: ya estamos juntos a la paga

Primera columna, v. 16

I: por tanto nos se te faga

II: por tanto no sete faga

Segunda columna, v. 21

I: en mi natura

II: por natura

\section{Glosa a la Copla XLI}

Segunda columna, v. 15

I: en mi natura

II: de tristura 


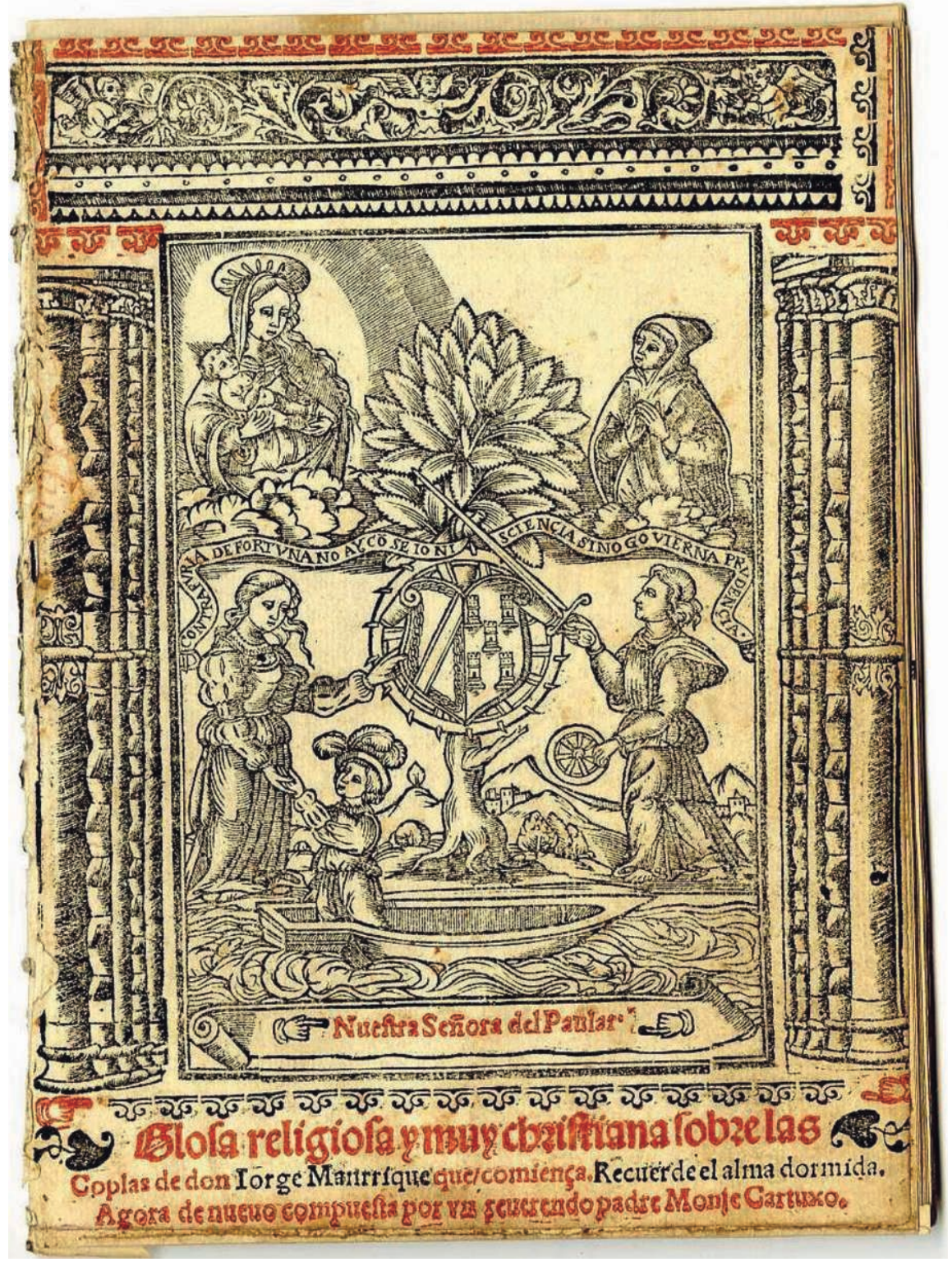

Fig. 1. - Glosa religiosa y muy christiana sobre las Coplas de don Iorge Manrrique, 1540, h. A1r: Portada

Ejemplar de la Hispanic Society of America (PQ 6412 .M6 V35 [bet. 1540-1552?]). Se agradece a la HSA el haber autorizado la reproducción de la imagen. 


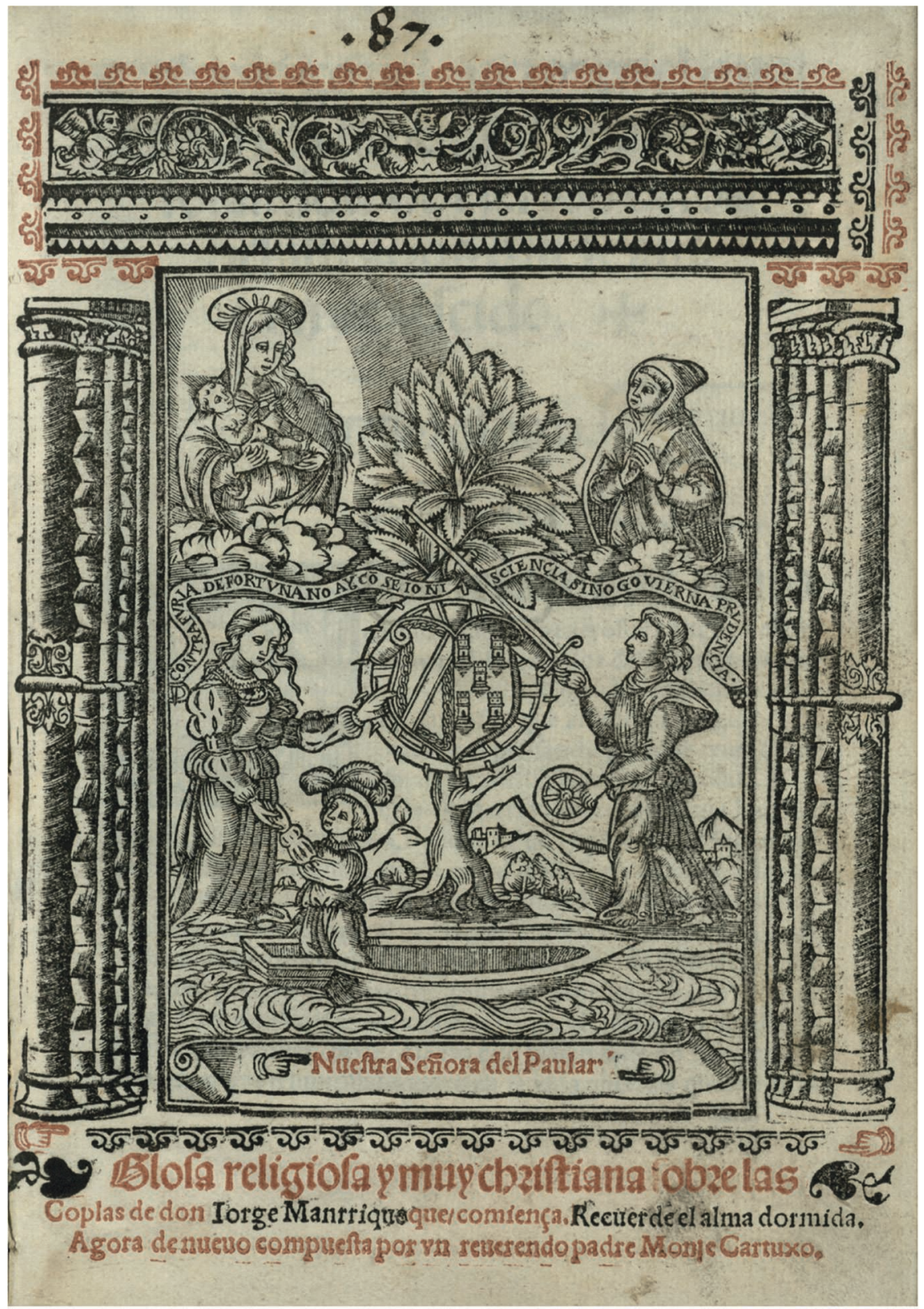

Fig. 2. - Glosa religiosa y muy christiana sobre las Coplas de don Iorge Manrrique, 1540, h. A1r: Portada.

Ejemplar de la Bayerische Staatsbibliothek (4 P.o.hisp. 50 n.). Se agradece a la Staatsbibliothek el haber autorizado la reproducción de la imagen. 
đâA gloxía y alabança oe oíos to: do podervio $p$ ocfu gloztofifinta madre $p$ fefioza nueftra/para entie da $y$ exemplo oenutuftras vidas fe acaba la excellétifima prouecbo fa y mu $\gamma$ contéplatiua glofa fobre las mozalidadcs $p$ boctrinas fas inofifimas de oon 3ozge danrrique que cōpufo y glofo el magni fico y mup reutécto padre el feños oónodrigo oc Galdepeñas me

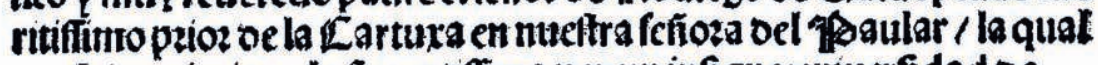
fe impzinio en la flozentifima $Y$ muY infigne vnutuerfidad oe

Zlcala oe Fenares ell cara oe zjoan oe Bzocar/ vift pximero $y$ apzouseta poz et mup reucrendo fefín el feñoz Licenciado "tpedro ocla frafca/celica: rio general en efta metropoli be $\widetilde{I}$ oledor

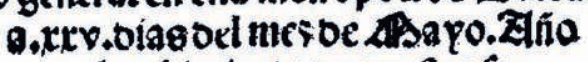
oel nafamiento oe nueftroles: ño2 Zु felu cbaifto de mill rquinientos q quarenta. $\therefore$

Fig. 3. - Glosa religiosa y muy christiana sobre las Coplas de don Iorge Manrrique, 1540, h. C8r: Colophon.

Ejemplar de la Bayerische Staatsbibliothek (4 P.o.hisp. 50 n.). Se agradece a la Staatsbibliothek el haber autorizado la reproducción de la imagen. 